\title{
The frontiers in brain imaging and neuromodulation: a new challenge
}

\author{
Ziad Nahas ${ }^{1,2 *}$ \\ 1 Department of Psychiatry, Mood Disorders Program and Brain Stimulation Laboratory, University of South Carolina, Charleston, SC, USA \\ 2 Department of Neuroscience, Medical University of South Carolina, Charleston, SC, USA \\ *Correspondence: nahasz@musc.edu
}

More than ever before, it is imperative to find effective treatments for most of our psychiatric disorders. Imagine that in 2020, and despite a widespread use of antidepressant treatments, the World Health Organization projects the burden of depression to become second only to ischemic heart disease (Hirschfeld, 1998; Greden, 2001). In fact, of the top ten causes for years lived in disability, three are psychiatric illnesses. Depression is second, but alcoholism and dementia are prominently featured too. Both bipolar disorder and schizophrenia will also continue to cause significant suffering. These psychiatric conditions are chronic and not fully responsive to treatments. Patients often relapse. The reasons for these dire projections lie primarily in the phenomenological approach of our diagnostic approach, our incomplete understanding of the heterogeneous pathophysiology of psychiatric illnesses and the limited efficacy of our therapeutic arsenals.

Modern scientific conceptualization of brain functions and localizations began to emerge from animal experiments, cadaver dissections, and clinical observations conducted by Broca (1865), Jackson (1873), and others in the mid 19th century. Ideas of regional brain functional localization and electrochemical neuronal transmission would later evolve into the contemporary neuronal network models that guide and inform much of the current applications of somatic treatments in neuropsychiatry. Over the past two decades, the rate of evolution of imaging technology and of study design has been breathtaking. Such investigations have shifted the debate from a reductionist "phrenology-like" attributions of mental phenomena, including psychiatric symptoms, to a broader dynamic interplay amongst various brain regions. Their utility in defining causation or providing tangible diagnostic tools for clinicians remain however very limited (Bullmore and Fletcher, 2003). This may be due in large part to restrictive sampling, study designs, and analytic methods. As the field matures, it has become apparent that the next challenges will have to integrate multimodal imaging techniques (Fox et al., 2009), cross-validations with genetic studies (Frodl et al., 2008) and a departure from crosssectional studies, in addition to data pooling to achieve representative sample sizes. The combination of transcranial magnetic stimulation (TMS) and other brain stimulation tools, also offers unique opportunities to move away from the correlative nature of imaging results (Bohning et al., 1998).

The use of somatic interventions to control or treat mental symptoms dates back to ancient times (Tourney, 1967; Clower and Finger, 2002). Evidence for burr holes drilled into the skull to "cure the demons" goes back to the Neolithic age. The notions that convulsions and fever may help mental disorders have been known since Hippocrates, while in medieval times, makebelieve surgeries were performed to extract the "stone of madness." The current status of non-pharmacological brain stimulation therapies to treat psychiatric conditions is also rapidly evolving. Research applications range from the benign (transcranial direct current stimulation, tDCS) (Been et al., 2007) to the invasive (deep brain stimulation, DBS) (Benabid et al., 2003) and cover a wide spectrum of disorders. Convulsive and sub-convulsive targeted brain stimulation treatments are inherently different from pharmacological interventions. An electrically stimulated cell will primarily produce a restricted range of responses inherent to its functionality (Ranck, 1975; Nahas et al., 2003a). Brain stimulation modulates the system's endogenous responsiveness and presumably, when delivered appropriately, allows it to recruit adaptive strategies. Random or deterministic influences (e.g., electrical stimuli, object presentation, or emotional deprivation) on biological systems have been shown to produce variable results depending on the type, intensity, frequency, and threshold of the stimulus. Long term potentiation (LTP) or long term depression (LTD) can alter synaptic plasticity and learning (Iadorola et al., 1986; Buzsaki et al., 1987; Huang et al., 2005). An optimal amount of added energy, whether it is electrical stimulation or "simulated noise," can enhance the detection of a weak signal, a phenomena known as stochastic resonance (Huber et al., 2003). As it stands electroconvulsive therapy (ECT) remains the most widely adopted clinical brain stimulation therapy. And while efficacious, the relapse rates associated with it are very high. Both TMS and vagus nerve stimulation (VNS) are US FDA approved for depression and DBS is approved for obsessive compulsive disorder (OCD) under a humanitarian device exemption. But TMS is an acute treatment for mild to moderate TRD (Oreardon et al., 2007), but not in TR-BD (Nahas et al., 2003b; George et al., 2009) and little is known about its role in maintenance therapy (Janicak et al., 2007). VNS on the other hand is a surgical procedure that delivers chronic treatment, is associated with relatively low relapse rates (Nahas et al., 2005) but is not supported by Class 1 evidence (Nahas et al., 2003b). The open reports of continuous high frequency DBS in depression and Tourette's syndrome and epidural cortical stimulation in depression are encouraging but preliminary.

One of the recurring themes within each of the techniques is the currently inadequate understanding of the translational neurobiological effects of the "use parameters." The future of this promising field will undoubtedly involve better translating the knowledge gained from preclinical cellular and non-human animal studies into clinical brain stimulation therapeutic uses. The challenge we face in developing these new treatments would be to maintain a kaleidoscopic perspective between the global 
and the discrete. Neurodynamics and the study of changes in neuronal organization and behavior over time can render a larger perspective (Freeman, 2003), however discrete electrochemical neuronal networks are responsible of various experiential phenomena. Ultimately, the response of the cell and its capacity to buffer stress will dictate the adaptability of the system and the way it achieves homeostasis:

Neural connectivity and neuromodulation have become integral frameworks by which the field conceptualizes neuropsychiatric diseases and treatment interventions. But a fundamental challenge remains: how do we relate the dynamic interplay among brain regions to understand cognitive, emotional, or behavioral regulation to effectively treat our patients and improve their quality of life. I dare to think that the future is promising.

\section{REFERENCES}

Been, G., Ngo, T., Miller, S., and Fitzgerald, P. (2007). The use of tDCS and CVS as methods of non-invasive brain stimulation. Brain Res. Rev. 56, 346-361.

Benabid, A. L., Vercucil, L., Benazzouz, A., Koudsie, A., Chabardes, S., Minotti, L., Kahane, P., Gentil, M., Lenartz, D., Andressen, C., Krack, P., and Pollak, P. (2003). Deep brain stimulation: what does it offer? Adv. Neurol. 91, 293-302.

Bohning, D. E., Shastri, A., Nahas, Z., Lorberbaum, J. P., Anderson, S. W., Dannels, W., Vincent, D. J., and George, M. S. (1998). Echoplanar BOLD fMRI of brain activation induced by concurrent transcranial magnetic stimulation (TMS). Invest. Radiol. 33, 336-340.

Broca, P., (1865). Sur le siege de la faculte du language articule. Bull Anthropol. 6, 377.

Bullmore, E., and Fletcher, P. (2003). The eye's mind: brain mapping and psychiatry. Br. J. Psychiatry 182, 381-384.

Buzsaki, G., Haas, H. L., and Anderson, E. G. (1987). Long-term potentiation induced by physiologically relevant stimulus patterns. Brain Res. 435, 331-333.

Clower, W. T., and Finger, S. (2002). Discovering trepanation: the contribution of Paul Broca. Neurosurgery 49, 1417-1425; discussion 1425-6 49:1417-1425; discuss.

Fox, M. D., Zhang, D., Snyder, A. Z., and Raichle, M. E. (2009). The global signal and observed anticorrelated resting state brain networks. J. Neurophysiol. 101, 3270-3283.

Freeman, W. J., (2003). Neurodynamic models of brain in psychiatry. Neuropsychopharmacology 28(Suppl. 1), S54-S63.

Frodl, T., M $\sqrt{ }$ aller, H. J., and Meisenzahl, E. (2008). Neuroimaging genetics: new perspectives in research on major depression? Acta Psychiatr. Scand. 118, 363-372.

George, M. S., Lisanby, S. H., Avery, D., McDonald, W. M., Durkalski, V., Pavlicova, M., Anderson, B., Nahas, Z., Bulow, P., Zarkowski, P., Holtzheimer, P., Schwartz, T., and Sackeim, H. A. (2009) "Daily left prefrontal TMS for major depression: a sham-controlled multisite randomized trial (NIH OPT-TMS)," in American College of Neuropsychopharmacology Annual Meeting, Hollywood, FL, p 149.

Greden, J.F., (2001). The burden of recurrent depression: causes, consequences, and future prospects. J. Clin. Psychiatry 62(Suppl. 22), 5-9.

Hirschfeld, R. M., (1998). American health care systems and depression: the past, present, and the future. $J$. Clin. Psychiatry 59(Suppl. 20), 5-10.

Huang, Y.Z., Edwards, M. J., Rounis, E., Bhatia, K. P., and Rothwell, J. C. (2005). Theta burst stimulation of the human motor cortex. Neuron 45, 201-206.

Huber, M. T., Braun, H. A., and Krieg, J. C. (2003). On episode sensitization in recurrent affective disorders: the role of noise. Neuropsychopharmacology 28(Suppl. 1), S13-S20.

Iadorola, M. J., Nicoletti, F., Naranjo, J. R., Putnam, F., and Costa, E. (1986). Kindling enhances the stimulation of inositol phospholipid hydrolysis elicited by ibotenic acid in rat hippocampal slices. Brain Res. 374, 174-178.

Jackson, J. H., (1873). Observations on the localisation of movements in the cerebral hemispheres. West Riding Lunatic Asylum Medical Reports 3, 175-190.

Janicak, P., Nahas, Z., Lisanby, S., Solvason, H., Sampson, S., McDonald, W., Marangell, L. B., Rosenquist, P. B., McCall, P., Kimball, V., Oreardon, J. P., Loo, C., Husain,
M. M., Krystal, A., Gilmer, W., Demitrack, M. A., and Schatzberg, A. F. (2007) "Durability of acute response to TMS in the treatment of major depression: relapse during a continuation pharmacotherapy extension study," in Society for Biological Psychiatry Annual Meeting (San Diego: Elsevier).

Nahas, Z., Kozel, F. A., and George, M. S. (2003a). "Somatic treatment in psychiatry," in Textbook of Biological Psychiatry, ed. J. Panksepp (New York: Wileys), p Chapter 17.

Nahas, Z., Kozel, F. A., Li, X., Anderson, B., and George, M. S. (2003b). Left prefrontal transcranial magnetic stimulation (TMS) treatment of depression in bipolar affective disorder: a pilot study of acute safety and efficacy. Bipolar Disord. 5, 40-47.

Nahas, Z., Marangell, L. B., Husain, M. M., Rush, A. J., Sackeim, H. A., Lisanby, S. H., Martinez, J. M., and George, M. (2005). Two-year outcome of vagus nerve stimulation (VNS) for treatment of major depressive episodes. J. Clin. Psychiatry 66, 1097-1104.

Oreardon, J., Solvason, H., Janicak, P., Sampson, S., Isenberg, K., Nahas, Z., McDonald, W., Avery, D., Fitzgerald, P., and Loo, C. (2007). Efficacy and safety of transcranial magnetic stimulation in the acute treatment of major depression: a multisite randomized controlled trial. Biol. Psychiatry 62, 1208-1216.

Ranck, J. B. Jr. (1975). Which elements are excited in electrical stimulation of mammalian central nervous system: a review. Brain Res. 98, 417-440.

Tourney, G., (1967). A history of therapeutic fashions in psychiatry, 1800-1966. Am. J. Psychiatry 124, 784-796.

Received: 13 July 2010; accepted: 14 July 2010; published online: 19 August 2010.

Citation: Nahas $Z$ (2010) The frontiers in brain imaging and neuromodulation: a new challenge. Front. Psychiatry 1:25. doi: 10.3389/fpsyt.2010.00025

This article was submitted to Frontiers in Neuropsychiatric Imaging and Stimulation, a specialty of Frontiers in Psychiatry.

Copyright (C) 2010 Nahas. This is an open-access article subject to an exclusive license agreement between the authors and the Frontiers Research Foundation, which permits unrestricted use, distribution, and reproduction in any medium, provided the original authors and source are credited. 